\title{
Proportion of patients without mental disorders being treated in mental health services worldwide
}

Ronny Bruffaerts, Jose Posada-Villa, Ali Obaid Al-Hamzawi, Oye Gureje, Yueqin Huang, Chiyi Hu, Evelyn J. Bromet, Maria Carmen Viana, Hristo Ruskov Hinkov, Elie G. Karam, Guilherme Borges, Silvia E. Florescu, David R. Williams, Koen Demyttenaere, Viviane Kovess-Masfety, Herbert Matschinger, Daphna Levinson, Giovanni de Girolamo, Yutaka Ono, Ron de Graaf, Mark Oakley Browne, Brendan Bunting, Miguel Xavier, Josep Maria Haro and Ronald C. Kessler

\section{Background}

Previous research suggests that many people receiving mental health treatment do not meet criteria for a mental disorder but are rather 'the worried well'.

\section{Aims \\ To examine the association of past-year mental health treatment with DSM-IV disorders.}

\section{Method}

The World Health Organization's World Mental Health (WMH) Surveys interviewed community samples of adults in 23 countries $(n=62305)$ about DSM-IV disorders and treatment in the past 12 months for problems with emotions, alcohol or drugs.

\section{Results}

Roughly half (52\%) of people who received treatment met criteria for a past-year DSM-IV disorder, an additional 18\% for a lifetime disorder and an additional 13\% for other indicators of need (multiple subthreshold disorders, recent stressors or suicidal behaviours). Dose-response associations were found between number of indicators of need and treatment.

\section{Conclusions}

The vast majority of treatment in the WMH countries goes to patients with mental disorders or other problems expected to benefit from treatment.

\section{Declaration of interest}

R.C.K. has been a consultant for Hoffman-La Roche, Johnson \& Johnson Wellness and Prevention, and Sanofi-Aventis, and has served on advisory boards for Mensante Corporation, Plus One Health Management, Lake Nona Institute and US Preventive Medicine. He owns a $25 \%$ share in DataStat.
Mental disorders are common around the world and burdensome for both the individual and society. ${ }^{1}$ Given the high prevalence of mental disorders globally, it is necessary to triage resources to those who need them most. ${ }^{2,3}$ Although undertreatment receives considerable attention, ${ }^{4-6}$ previous studies suggest that between one-third and half of the patients who are treated for mental disorders do not meet formal criteria for such disorders ${ }^{7-12}$ and that $3-14 \%$ of people without a mental disorder receive treatment for problems with emotions or the use of substances in a given year. ${ }^{1,13}$ However, these data are far from conclusive in arguing that a high proportion of treatment going to patients with low need. This is true for several reasons. First, most studies failed to assess other indicators of need for treatment besides diagnoses (for example recent stressors or suicidal behaviours). This is important because mental disorders are not the only indicators of need for treatment. ${ }^{14,15}$ Second, most previous studies did not provide information about the sector in which patients who failed to meet full criteria for a disorder received their treatment. This is important because treatment of such patients in the human services sector (such as spiritual counselling during normal bereavement) or the self-help sector (such as participation in a trauma survivor support group) would not be seen as inappropriate. Third, most of these studies were carried out in a small set of countries (mostly the USA, ${ }^{7,9}$ but also Canada ${ }^{14,16}$ Germany, The Netherlands, Chile ${ }^{13}$ and Australia). ${ }^{17}$ As far as we are aware, no global data exist that examines the proportion of treatment for problems with emotional issues or substance use received by those patients who fail to meet full criteria for a mental disorder. Such a study is especially timely in an era when governments, policymakers and healthcare planners face competing priorities and economic constraints. ${ }^{2}$ Data are reported here on these issues based on an analysis of data collected in the World Health
Organization (WHO) World Mental Health (WMH) surveys. The WMH surveys are general population surveys that used structured psychiatric interviews, validated for use worldwide, to measure the presence of mental disorders as well as treatment for problems with emotions or for substance use. The current study builds on earlier WMH studies reporting on the crossnational treatment of mental disorders ${ }^{1,3,5}$ by investigating treatment of people without mental disorders. The specific aims of the study were to investigate the proportion of patients in treatment for problems with emotions or substance use at anytime in the 12 months before interview who failed to meet criteria for a $\mathrm{DSM}^{-\mathrm{IV}^{18}}$ disorder at any time during that 12 -month period, to investigate other indicators of need among these patients, to examine the sectors of treatment as well as the frequency and duration of their use of services, and to examine their self-reported reasons for seeking treatment.

\section{Method}

\section{Survey respondents}

The WMH surveys were carried out in 23 countries in six continents, including: Africa (Nigeria (field dates 200-2003), South Africa (field dates 2003-2004); Asia (Israel (field dates 2002-2004), Iraq (field dates 2006-2007), Japan (field dates 2002-2006), Lebanon (field dates 2002-2003), Beijing (field dates 2002-2003), Shanghai (field dates 2002-2003) and Shenzhen (Peoples Republic of China, field dates 2006-2007)); New Zealand (field dates 2003-2004); Europe (Belgium (field dates 2001-2002), Bulgaria (field dates 2003-2007), France (field dates 2001-2002), Germany (field dates 2002-2003), Italy (field dates 2001-2002), Portugal (field dates 2008-2009), The Netherlands (field dates 2002-2003), Northern Ireland (field dates 2004-2007), Romania 
(field dates 2005-2006), Spain (field dates 2001-2002), Ukraine (field dates 2002); and North and South America (Brazil (field dates 2005-2007), Colombia (field dates 2003), Mexico (field dates 2001-2002) and the USA (field dates 2002-2003)). Respondents were selected using a stratified multistage clustered-area probability sampling strategy, apart from Japan, where an unclustered two-stage probability sampling method was used. The total sample size was 118907 with individual country sample sizes ranging from 2357 in Romania to 12790 in New Zealand. The weighted average response rate across all countries was $71.5 \%$. Using World Bank criteria, ${ }^{19}$ countries were classified as low-income (Colombia, Iraq, Nigeria, China and Ukraine), middle-income (Brazil, Bulgaria, Lebanon, Mexico, Romania and South Africa), and high-income countries (all other survey countries) (see online Table DS1).

Surveys were conducted face-to-face by trained lay interviewers. Informed consent was obtained before the start of the interview. Internal subsampling was used to reduce respondent burden by dividing the interview into two parts. Part 1 (all respondents) included sociodemographic variables, the core diagnostic assessment of mental disorders and suicidal behaviours. All Part 1 respondents who met criteria for any lifetime mental disorder and a probability sample of other respondents were administered Part 2. Part 2 included additional information on access to care. Part 2 respondents were weighted by the inverse of their probability of selection for Part 2 of the interview to adjust for differential sampling. Analyses in this study were based on the weighted Part 2 subsample $(n=62305)$. Additional weights were used to adjust for differential probabilities of selection within households, to adjust for non-response and to match the samples to population sociodemographic distributions. Further details of the survey design are reported elsewhere. ${ }^{20-22}$

The WHO back translation protocol was used to translate instruments and training materials. Translations were performed by individuals who were bilingual, with consultation to expert panels (with psychiatrists, psychologists and mental health researchers). The following steps were performed: translation from the original (English version into the target language by two independent translators), review of these translations by a group of bilingual people and production of a revised version, translation of the revised version back into English by two different translators; and review of the back translations and production of a final version by the group of bilingual individuals. This protocol was followed in order to obtain instruments with acceptable cross-cultural validity for use worldwide.

\section{Measures}

\section{Mental health service utilisation}

Treatment utilisation was assessed by the Composite International diagnostic Interview (CIDI) Version 3.0 treatment module. ${ }^{23}$ Respondents were asked if they received either out-patient or in-patient treatment for problems with emotion regulation, anxiety, psychological distress or use of alcohol or drugs from any providers including mental health professionals (such as psychiatrist, psychologist), general medical professionals (such as general practitioner, occupational therapist) and other nonhealthcare professionals (such as religious counsellors, traditional healers, complementary or alternative medicine (CAM)). Examples of these types of providers were presented in a respondent booklet as a visual recall aid. Among those who reported to have used services, follow-up questions were asked about ages at the first and most recent contacts and the number of visits in the past 12 months. Reports of any service use in the past 12 months were classified into the following predefined categories: psychiatrist, non-psychiatrist mental health specialist (psychologist or other non-psychiatrist mental health professional in any setting, social worker or counsellor in a mental health specialty setting and use of a mental health hotline), general medical provider (primary care doctor, other general medical doctor, nurse and any other health professional not previously mentioned), human services professional (religious or spiritual advisor and social worker or counsellor in any setting other than a specialty mental health setting), and CAM (any other type of healer, such as a chiropractor, participation in an internet support group or participation in a self-help group). Those respondents who reported that they received services in the past 12 months were also asked to indicate which of the following reasons they had for seeing a professional: because of emotional problems/ problem behaviour, to deal with general bodily complaints, to help making life decisions, to cope with ongoing stress, to cope with stressful events, to come to terms with the past or seeking help because others urged them to.

\section{Mental disorders}

DSM-IV diagnoses were made using the fully structured layadministered CIDI 3.0 diagnostic interview. The DSM-IV criteria were used to generate both lifetime diagnoses and diagnoses of disorders present at any time in the 12 months before interview (referred to as 12-month disorders). DSM-IV/CIDI disorders considered herein include: mood disorders (bipolar type I and II disorders, major depressive disorder and dysthymia), anxiety disorders (panic disorder, agoraphobia without panic, specific phobia, social phobia, generalised anxiety disorder, obsessivecompulsive disorder, post-traumatic stress disorder and adult separation anxiety disorder), impulse control disorders (anorexia, bulimia, binge eating disorder, oppositional defiant disorder, intermittent explosive disorder and pathological gambling disorder) and substance use disorders (alcohol and drug misuse with or without dependence). Only broad diagnostic categories were included as covariates in the statistical models. All diagnoses were made using organic exclusions and diagnostic hierarchy rules, except for the substance use disorders, in which misuse was defined with or without dependence. Masked clinical reappraisal interviews using the Structured Clinical Interview for DSM-IV (SCID) showed generally good concordance between diagnoses based on the CIDI and the SCID for anxiety, mood and substance use disorders. ${ }^{24}$

\section{Need for treatment}

Because clinical need is a heterogeneous concept that goes beyond the mere criteria of a mental disorder, ${ }^{25,26}$ we complemented the assessment of 12-month mental disorders with other possible need indicators that included exposure to stressful events in the past 12 months, suicidality in the past 12 months (either ideation, plans or attempts), lifetime (but not 12-month) mental disorders, along with other self-reported reasons why people may seek treatment (see online Table DS2). Respondents who did not meet the 12-month criteria for any of the abovementioned DSM-IV/CIDI disorders were divided into subsamples based on a three-category gradient of possible need for treatment: (a) those with at least one lifetime DSM-IV disorder, (b) those without a lifetime DSM-IV disorder but with one or more indicators of severity (i.e. 12-month subthreshold disorders (defined as lacking only one criterion for a diagnosis), exposure to a major stressful event, such as rape or divorce, in the past 12 months, or lifetime admission to hospital for a mental disorder); and (c) the remaining respondents. Respondents were thus grouped into four levels of increasing need for treatment: (a) respondents with any 12 -month mental disorder, (b) respondents with a past mental 
disorder (i.e. a lifetime mental disorder without a 12-month mental disorder), (c) respondents without mental disorder (either 12-month or past) but with any other indicator of need for treatment, or (d) those without any indicator of need for treatment.

\section{Statistical methods}

Basic patterns of service use were examined by calculating proportions of people in treatment and mean numbers of visits among those in treatment. Logistic regression analysis was used to study predictors of 12-month treatment and treatment in particular sectors. Standard errors were estimated using the Taylor series method ${ }^{27}$ for adjusting the weighting as well as for the geographic clustering of observations both between and within countries. These adjustments were implemented using the SUDAAN software system (version 8.0.1 for Unix). The coefficients in the logistic regression equations and their design-based standard errors were transformed into odds ratios (ORs) and 95\% confidenceintervals for ease of interpretation. Multivariate significance tests in the logistic regression analyses were made using Wald $\chi^{2}$ tests based on coefficient variancecovariance matrices, adjusted for design effects using the Taylor series method. Statistical significance was evaluated using two-sided design-based tests and a 0.05 level of significance.

\section{Results}

\section{2-month treatment patterns}

The overall 12 -month treatment rate is $9.2 \%$, with a significant monotonic association between need for treatment and the probability of being treated (Table 1); among those with a 12 -month mental disorder, $27.4 \%$ reported that they had received services in the past year, compared with $12.0 \%$ among those with a lifetime disorder. Lower rates were found in people with lower need for treatment. Despite the fact that we found lower treatment rates in lower-income countries, the association between need for treatment and the probability of receiving treatment was consistent in all three income categories (online Tables DS3a-c).

Of all people in treatment, $52.4 \%$ met criteria for a 12 -month and $18.4 \%$ met criteria for a past mental disorder, a finding that was slightly more pronounced in high-income countries where $55.4 \%$ of those in treatment met criteria for a 12 -month mental disorder compared with 45.4 and $47.6 \%$ in middle- and low- income countries, respectively (see online DS3a-c). Approximately $16 \%$ did not report any need for treatment nor a 12 -month or lifetime disorder. Individuals without disorders have in general fewer visits than those with disorders, suggesting that the resource allocation for people without disorders is much lower than their percentage in treatment. For example, individuals without any need for treatment represent $15.9 \%$ of those in treatment but get only $10.4 \%$ of all visits. They are also much less likely to see a psychiatrist (Table 2), which suggests that they take up an even lower proportion of specialty visits. Interestingly, similar results were found after disaggregation for income (see online Tables DS3a-c and DS4a-c).

Respondents with 12-month mental disorders accounted for higher proportion of visits to a psychiatrist (i.e. $72.2 \%$ ) than to other types of service providers including other mental health providers $(66.8 \%)$, general medicine $(59.5 \%)$, human services $(57.7 \%)$ or CAM providers $(62.8 \%)$ (Table 2$)$. An inverse pattern was found for respondents with past mental disorder: they accounted for higher proportions of visits to CAM providers $(23.3 \%)$ than to formal healthcare providers (all within the 12.0-16.3\%). Respondents classified as those without treatment need accounted for the highest proportion of visits to human services $(19.3 \%)$ than to any of the other types of providers, but after disaggregation for income, this was found to be the case only in high- and low-income countries (see Tables DS4a-c).

These differences are reflected in the treatment profiles across the different groups of treatment need indicators (Table 3). First, among people with a 12 -month disorder, $51.3 \%$ of the visits are delivered by a mental health specialist (either a psychiatrist $(22.1 \%)$ or another mental healthcare provider $(29.2 \%))$. The comparable figure for people without any need indicator is $38.9 \%$. Thus, the proportion of treatment visits in mental healthcare is consistently lower among those individuals without any need indicator compared with those with the highest need. Again, similar patterns were found when looking at these association for income categories separately (see online Tables DS4a(bis)-c(bis)). Second, formal healthcare remains a central treatment setting, even for respondents with less or even absent indicators for treatment need. On average, $68.5 \%$ of all visits (regardless of the need category) were delivered by formal healthcare providers (psychiatrist, other mental healthcare or general medicine). After disaggregating for need category, comparable figures were $70.0 \%$ for those with a 12 -month mental disorder, $60.6 \%$ for those with a lifetime mental disorder, $72.6 \%$ for those with any need for treatment and $67.3 \%$ for those in the lowest need category.

\section{Predictors of treatment in respondents without 12-month disorders}

In general, the odds of treatment receipt were higher in female respondents and those older than 30 and lower in individuals with a lower number of years of education (Table 4). Lifetime admission to hospital (ORs in the range 4.1-13.6) and multiple subthreshold disorders (ORs in the range 2.6-5.1) were the most powerful predictors of receiving services (Table 5), followed by past year suicidality (ORs in the range 1.4-2.5) and psychosocial stressors in the past year (ORs in the range 1.7-2.3). In addition, among those with a lifetime disorder, receiving treatment was also associated with lifetime mood disorders (ORs in the range 1.3-2.0) and recency of the lifetime disorders (i.e. the more recent the disorder, the higher the odds of being treated - ORs in the range 1.6-1.7). For the most part, predictors of treatment were similar across income categories, and the strength of the associations remained fairly similar in countries with different income levels (see online Table DS5).

We computed a weighted estimate of treatment need by summing the indicators of treatment need based on the weights from the ORs from Table 5. By doing so we could see whether there was an association between the weighted estimate of need among those with lifetime but no 12-month disorder or among those with no lifetime or 12-month disorder on the one hand and the probability of receiving 12-month treatment on the other. Across income categories, we found a statistical significant strong monotonic relationship between the weighted estimate of need for treatment among those with no 12 -month disorder and the probability of receiving 12-month treatment (Tables 6 and 7, online Tables DS6a-c and DS7a-c). People with the highest need scores were systematically eight times more likely to be in treatment compared with people with the lowest need scores. Indeed, the smallest proportion of respondents with the highest need had systematically the highest probability of receiving treatment and, on average, the highest number of visits.

\section{Reasons for seeking treatment}

Across country income categories, emotional problems/problem behaviours were the most important reason for seeking mental healthcare (see Table 8), with a higher percentage of those with 

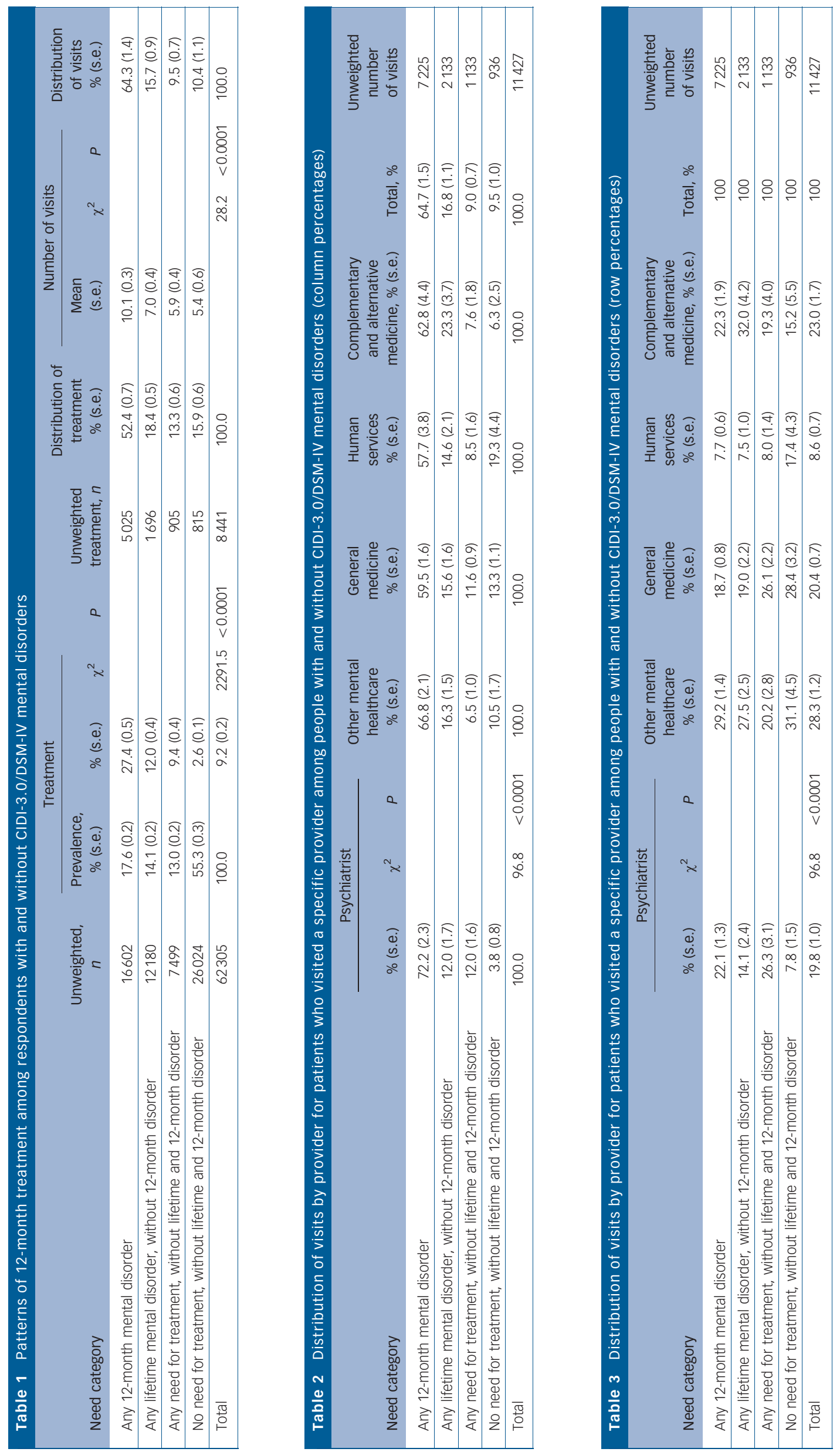
Table 4 Sociodemographic predictors of 12-month service use for mental disorders or emotional problems among respondents without 12-month CIDI-3.0/DSM-IV mental disorders

\begin{tabular}{|c|c|c|c|c|c|c|}
\hline & \multicolumn{3}{|c|}{$\begin{array}{l}\text { Respondents with lifetime } \\
\text { mental disorders }\end{array}$} & \multicolumn{3}{|c|}{$\begin{array}{l}\text { Respondents without mental disorders } \\
\text { but with a need for treatment }\end{array}$} \\
\hline & Odds ratio $(95 \% \mathrm{Cl})$ & $\chi^{2}$ & $P$ & Odds ratio $(95 \% \mathrm{Cl})$ & $\chi^{2}$ & $P$ \\
\hline Gender & & 26.7 & $<0.001$ & & 40.1 & $<0.001$ \\
\hline Female & $1.5(1.3-1.7)$ & & & $1.6(1.4-1.8)$ & & \\
\hline Male & 1.0 (ref) & & & 1.0 (ref) & & \\
\hline Income & & 0.6 & 0.896 & & 4.8 & 0.191 \\
\hline Low & $1.0(0.8-1.3)$ & & & $1.0(0.8-1.2)$ & & \\
\hline Low average & $1.0(0.8-1.2)$ & & & $0.9(0.7-1.1)$ & & \\
\hline High average & $1.0(0.8-1.2)$ & & & $0.8(0.7-1.0)$ & & \\
\hline High & 1.0 (ref) & & & 1.0 (ref) & & \\
\hline Education, years & & 11.7 & 0.009 & & 11.8 & 0.008 \\
\hline $0-11$ & $0.7(0.6-0.9)$ & & & $0.7(0.5-0.8)$ & & \\
\hline 12 & $0.8(0.7-1.0)$ & & & $0.8(0.7-1.0)$ & & \\
\hline $13-15$ & $1.0(0.8-1.1)$ & & & $0.9(0.7-1.0)$ & & \\
\hline$\geqslant 16$ & 1.0 (ref) & & & 1.0 (ref) & & \\
\hline Marital status & & 3.2 & 0.206 & & 6.2 & 0.045 \\
\hline Separated/widowed/divorced & $1.1(0.9-1.4)$ & & & $1.1(0.9-1.4)$ & & \\
\hline Never married & $1.1(0.9-1.4)$ & & & $1.3(1.0-1.6)$ & & \\
\hline Married & 1.0 (ref) & & & 1.0 (ref) & & \\
\hline Age & & 34.0 & $<0.001$ & & 24.8 & $<0.001$ \\
\hline $30-44$ & $1.9(1.5-2.4)$ & & & $1.5(1.2-1.9)$ & & \\
\hline $45-59$ & $2.1(1.6-2.7)$ & & & $1.8(1.5-2.4)$ & & \\
\hline $60+$ & $1.9(1.4-2.6)$ & & & $1.5(1.2-2.0)$ & & \\
\hline$<30$ & 1.0 (ref) & & & 1.0 (ref) & & \\
\hline
\end{tabular}

Table 5 Clinical predictors of 12-month service use for mental disorders or emotional problems among respondents without 12-month CIDI-3.0/DSM-IV mental disorders

\begin{tabular}{|c|c|c|c|c|c|c|}
\hline & \multicolumn{3}{|c|}{$\begin{array}{l}\text { Respondents with lifetime } \\
\text { mental disorders }\end{array}$} & \multicolumn{3}{|c|}{$\begin{array}{l}\text { Respondents without mental disorders } \\
\text { but with a need for treatment }\end{array}$} \\
\hline & Odds ratio $(95 \% \mathrm{Cl})$ & $\chi^{2}$ & $P$ & Odds ratio $(95 \% \mathrm{Cl})$ & $\chi^{2}$ & $P$ \\
\hline Lifetime bipolar disorder & & 11.0 & 0.001 & - & & \\
\hline Yes & $1.8(1.3-2.5)$ & & & - & & \\
\hline No & 1.0 (ref) & & & - & & \\
\hline Lifetime depression/dysthymia & & 41.8 & $<0.001$ & - & & \\
\hline Yes & $1.7(1.4-2.0)$ & & & - & & \\
\hline No & 1.0 (ref) & & & - & & \\
\hline Lifetime anxiety disorder & & 23.3 & $<0.001$ & - & & \\
\hline 1 Lifetime anxiety disorder & $1.3(1.1-1.6)$ & & & - & & \\
\hline$\geqslant 2$ lifetime anxiety disorders & $2.0(1.5-2.6)$ & & & - & & \\
\hline No lifetime anxiety disorder & 1.0 (ref) & & & - & & \\
\hline Lifetime behavioural disorder & & 2.0 & 0.364 & - & & \\
\hline 1 lifetime behavioural disorder & $1.2(0.9-1.6)$ & & & - & & \\
\hline$\geqslant 2$ lifetime behavioural disorders & $1.1(0.6-2.0)$ & & & - & & \\
\hline No lifetime behavioural disorder & 1.0 (ref) & & & - & & \\
\hline Lifetime substance disorder & & 1.1 & 0.573 & - & & \\
\hline Lifetime substance abuse disorder & $1.1(0.9-1.4)$ & & & - & & \\
\hline Lifetime substance dependence disorder & $1.1(0.8-1.5)$ & & & - & & \\
\hline No lifetime substance disorder & 1.0 (ref) & & & - & & \\
\hline Recency of the lifetime mental disorder, year & & 31.9 & $<0.001$ & - & & \\
\hline 1 & $1.7(1.3-2.2)$ & & & - & & \\
\hline $2-4$ & $1.6(1.3-1.9)$ & & & - & & \\
\hline $5-9$ & $1.1(0.9-1.4)$ & & & - & & \\
\hline $10+$ & 1.0 (ref) & & & - & & \\
\hline Subthreshold mental disorders & & 63.1 & $<0.001$ & & 214.7 & $<0.001$ \\
\hline 1 Subthreshold mental disorder & $1.8(1.5-2.1)$ & & & $2.9(2.5-3.5)$ & & \\
\hline$\geqslant 2$ subthreshold mental disorders & $2.6(1.9-3.6)$ & & & $5.1(3.8-7.0)$ & & \\
\hline No subthreshold disorders & 1.0 (ref) & & & 1.0 (ref) & & \\
\hline Lifetime mental health admission to hospital & & 215.0 & $<0.001$ & & 353.5 & $<0.001$ \\
\hline Yes & $4.1(3.4-4.9)$ & & & $13.6(10.4-17.9)$ & & \\
\hline No & 1.0 (ref) & & & 1.0 (ref) & & \\
\hline Any psychosocial stressor in the past year & & 43.9 & $<0.001$ & & 95.3 & $<0.001$ \\
\hline Yes & $1.7(1.5-2.0)$ & & & $2.3(1.9-2.7)$ & & \\
\hline No & 1.0 (ref) & & & 1.0 (ref) & & \\
\hline Any suicidality in the past year & & 4.4 & 0.035 & & 51.9 & $<0.001$ \\
\hline Yes & $1.4(1.0-1.8)$ & & & $2.5(1.9-3.2)$ & & \\
\hline No & 1.0 (ref) & & & 1.0 (ref) & & \\
\hline
\end{tabular}




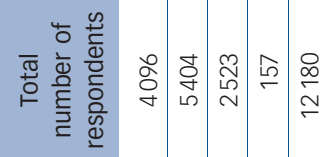

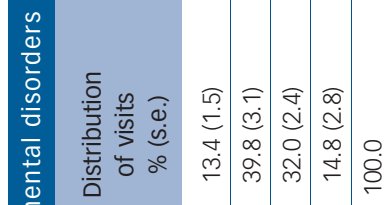

을

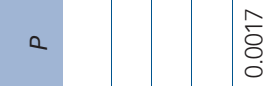

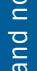

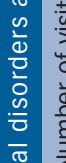

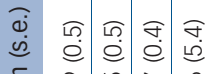

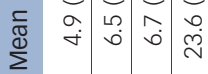

亯

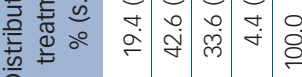

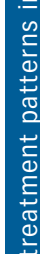

吾

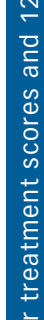

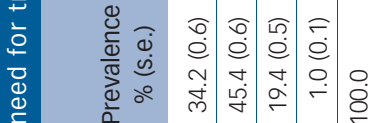

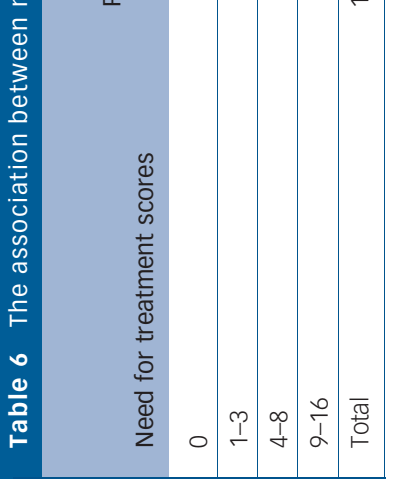

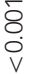

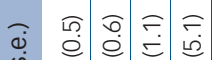

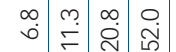

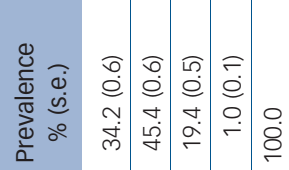

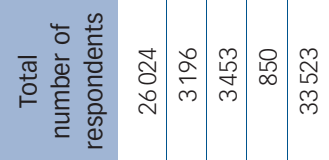

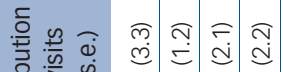

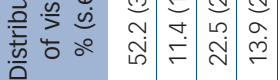

a

¿্.

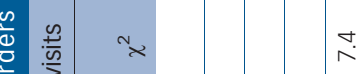

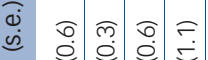

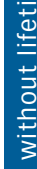

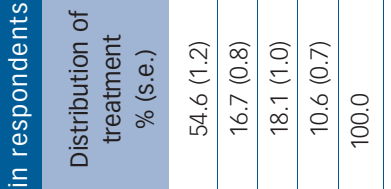

竞

选

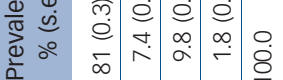

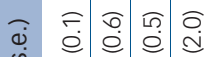

눈

흠

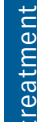

$\frac{10}{2}$

这

$\sum_{0.0}^{\bar{\Phi}}$

을

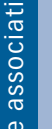

$\stackrel{\infty}{\stackrel{\infty}{上}}$

衣
焉

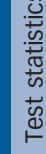

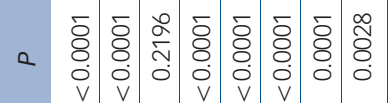

×

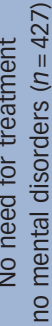

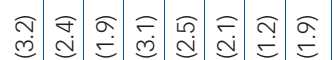

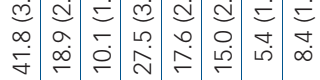

๑

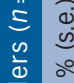

要

은 는

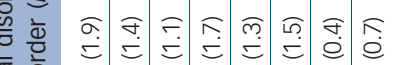

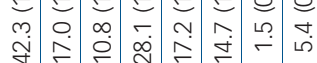

E

空

密

खे

푱

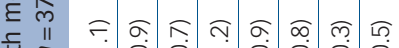

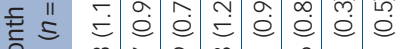

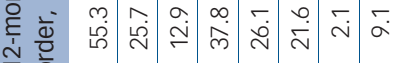

要离

응 흘

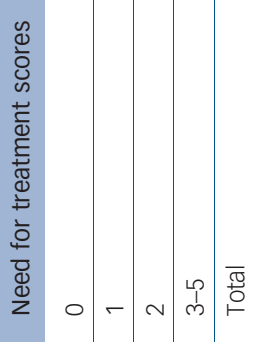

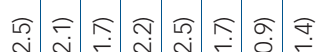

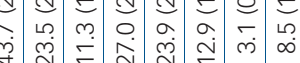


a 12 -month mental disorder endorsing this item (i.e. 55.3\%) compared with lower need groups (41.8-43.7\% range).Only a minority of all treated respondents (between 5.4 and 9.1\%) sought help because others urged them to, suggesting that the majority perceived a need for treatment that brought them into contact with providers. Other common reasons included to cope with ongoing stress and stressful events (especially in high- and middle-income countries) and dealing with bodily complaints (especially in middle- and low-income countries, see online Tables DS8a-c).

\section{Discussion}

\section{Main findings}

This first cross-national population-based survey revealed that most people in mental healthcare actually meet criteria for a 12-month or past mental disorder. Interestingly, this is a consistent finding across countries with marked differences in economic situations, culture, attitudes towards mental illness and organisation of healthcare. Among those receiving treatment, 16\% (with ranges between $12 \%$ in high-income and $17 \%$ in low-income countries) do not meet criteria for a mental disorder and do not report any need for treatment.

\section{Limitations}

The results presented here should be interpreted in the light of the following limitations. First, respondents who did not speak the primary language(s) of the country sufficiently, those institutionalised and those without a fixed address were not included in this study. It may be that such people have different patterns of service use or need for treatment. Moreover, against the background that the need for treatment is elevated in in-patients or specific groups (like those with psychotic disorder or borderline personality disorder), the treatment patterns we found in this study only apply for those mental disorders and need variables included in the CIDI-3.0. Second, the CIDI-3.0 treatment module asks for treatment for emotional or substance misuse problems and not for other reasons like suicidality. In addition, people may have had other reasons that they sought treatment for than those we included. This means that some true cases might have been incorrectly classified as non-cases. Moreover, the data on treatment did not include information about the adequacy or effectiveness of the treatment received. Further research should therefore focus in more detail on received treatment for both mental disorders and other indicators of treatment need and criteria defining treatment adequacy/ effectiveness. Third, responses to the survey may have been biased by the use of retrospective self-reports. Previous studies have shown that the validity of the assessment of service use could be biased dependent upon recall time periods ${ }^{28}$ or frequency of service use, all leading to a modest underestimation of more recent service use. ${ }^{29}$ It is important to note that this kind of recall failure would mean that our estimates are conservative; that is, that an even smaller proportion of people with recent treatment than we actually estimated had no evidence of a disorder either in the past year or in their lifetime. A fourth limitation is that the countries included in the present study are not representative of all the countries in the world. This may imply that our conclusions may not hold for every nation. A final limitation is that results may have been altered with secular changes such as those introduced by the global economic recession that began in $2008 .^{30}$

\section{Significance of our findings}

Our data are in line with previous reports ${ }^{1,3,13}$ in demonstrating that a considerable proportion of mental service users do not have a 12-month mental disorder. However, after including other indicators of treatment need, a more refined picture emerges: almost one in five meet criteria for a lifetime mental disorder and another one in seven reports a clinical need for treatment. Also the observed dose-response association between indicators of need for treatment and the probability of receiving treatment from the specialised mental health sector is comparable with the existing literature, ${ }^{10,12,13,16}$ but it is noteworthy that previous studies were mostly performed in high-income countries. Our findings extend available knowledge by suggesting that the gradient between need for treatment and the probability of receiving (specialised) treatment may be a phenomenon that goes beyond economic and cultural differences, but also beyond differences in the organisation of local mental healthcare systems.

Roughly one in five of those in treatment had lifetime (but not 12-month) mental disorders. That respondents with more recent lifetime disorders were up to $70 \%$ more likely to be in 12 -month treatment suggests that these people might be still in treatment for their recent episode of mental disorder, and may thus reflect long-term treatment approaches that eventually may serve as relapse prevention. ${ }^{10}$ The finding that lifetime mental health or admission to hospital for substance misuse was the strongest predictor of 12-month treatment in the absence of mental disorder is also in line with this interpretation.

Even though $15.9 \%$ of people in treatment have neither a mental disorder nor evidence of serious problems that would require treatment, these people make up only $10.4 \%$ of all visits. Only $7.8 \%$ are treated by a psychiatrist because of the lower intensity of their treatment compared with that of people with disorders or significant problems. Across income categories, between 14 and $21 \%$ of treated respondents did not have any indication of treatment need. Although this estimate was clearly higher than the estimate obtained in a US national sample, ${ }^{10}$ it is notable that these patients only accounted for $9-17 \%$ of all visits. Interestingly, the vast majority of these patients received care from a formal healthcare setting, suggesting that they contribute to formal healthcare expenditures. On the one hand, this does not necessarily have to be a problem since it might be that these people still have substantial functional impairment after having received adequate treatment in the past. ${ }^{31}$ On the other hand, however, given that half of serious cases of mental illness are untreated, ${ }^{3}$ the question could be raised to what extent (mostly reimbursed) formal healthcare is the appropriate treatment setting for patients that did not report any need for treatment. After all, in times of economic restraints and limited financial resources, more emphasis may be given to (re)allocate resources to those with the highest needs or people who are especially at risk for developing mental disorders like younger cohorts, females or those with lower educational attainment. ${ }^{32}$ Instead, we found that those treated were older, higher-educated females who are in general at lower risk for developing serious emotional problems. This suggests that at least a part of the treatment resources may be misallocated and that this may be more pronounced in high-income countries. However, this is not a suggestion to omit mild emotional problems from mental healthcare ${ }^{33}$ but rather a suggestion that formal healthcare for mild disorders could be more focused on those who are at risk of developing more serious emotional problems.

Across country income levels and across different levels of need for treatment, respondents reported similar reasons for seeking help, with emotions/problem behaviour as the most common reason for seeking help. Also, only a minority (i.e. between 5 and 9\%) sought help because others urged them to. That in middle- and low-income countries, apart from emotional reasons, also bodily complaints appeared to be symptoms that drove people into treatment for their emotional problems suggests 
that the association between bodily complaints, emotional problems and the need for treatment may be moderated by cultural factors ${ }^{34}$ or societal values. ${ }^{35}$ Further research may focus on a more refined cultural diversity of the interplay between particular cultural ethics, the expression of emotional problems and the association with subjective reasons for seeking help. For instance, one area that might be a focus for further study is the effect of family and/or community reactions on the process of seeking help when an individual has a mental disorder.

In an era where healthcare expenditures are raising progressively around the globe, the question how much a society can afford to guarantee its citizens effective mental healthcare becomes important. Against previous concerns that a considerable portion of service users would not meet criteria for mental disorders, we found some reassuring data regarding overtreatment in mental healthcare: most of the people treated in the mental health sector either meet criteria for a mental disorders or have a specific need for treatment. This does not mean that resources are fully used in an effective and efficient way as we found that $67 \%$ of the treatment visits of the people without need take place in (mostly reimbursed) formal healthcare, but also that $22 \%$ of the visits of people with mental disorders take place in CAM settings. Not only overtreatment but also suboptimal care may be regarded as wasting resources that prevent effective and efficient mental healthcare. ${ }^{36}$ Towards this end, careful work is needed to ensure that the right treatment goes to the right people who need it, rather than focusing on the wrong people in treatment. Evidently, we should always bear in mind that optimal treatment allocation rules are not obvious and constantly need to be considered in terms of short- and long-term benefits of an intervention.

Ronny Bruffaerts, PhD, Universitair Psychiatrisch Centrum - KULeuven (UPC-KUL), Leuven, Belgium; Jose Posada-Villa, MD, Colegio Mayor de Cundinamarca University, Bogota, Colombia; Ali Obaid Al-Hamzawi, DM, FICMSAl-Qadisia University College of Medicine, Diwania, Iraq; Oye Gureje, MD, PhD, DSC, FRCPsych, WHO Collaborating Centre for Research and Training in Mental Health, Neurosciences, and Drug \& Alcohol Abuse, Department of Psychiatry, University College Hospital, Ibadan, Nigeria; Yueqin Huang, MD, MPH, PhD, Institute of Mental Health, Key Laboratory of Ministry of Health, Peking University, Haidian, Beijing, China; Chiyi Hu, MD, PhD, Shenzhen Institute of Mental Health and Shenzhen Kangning Hospital, Guangdong Province, PR China; Evelyn J. Bromet, PhD, State University of New York at Stony Brook, Department of Psychiatry, New York, USA; Maria Carmen Viana, MD, PhD, Department of Social Medicine, Federal University of Espírito Santo (UFES), Vitória, Espírito Santo, Brazil; Hristo Ruskov Hinkov, MD, PhD, National Center for Public Health and Analyses, Sofia, Bulgaria; Elie G. Karam, MD, St. George Hospital University Medical Center, Balamand University, Faculty of Medicine, Institute for Development, Research, Advocacy \& Applied Care (IDRAAC), Medical Institute for Neuropsychological Disorders (MIND), Beirut, Lebanon; Guilherme Borges, MSC, DrSc, Division of Epidemiological and Psychosocial Research, National Institute of Psychiatry (Mexico) \& Metropolitan Autonomous University, Mexico City, Mexico; Silvia E. Florescu, MD, PhD, National School of Public Health, Management and Professional Development, 31 vaselor Street, Bucharest, Romania; David R. williams, MPH, PhD, Department of Social and Behavioral Sciences, Harvard Williams, MPH, PhD, Department of Social and Behavioral Sciences,
school of Public Health, Boston, USA; Koen Demyttenaere, MD, PhD, Universitair Psychiatrisch Centrum - KULeuven (UPC-KUL), Leuven, Belgium; Viviane Kovess-Masfety, MD, PhD, EA 4069 Université Paris Descartes \& EHESP School for Public Health Department of Epidemiology, Paris, France; Herbert Matschinger, PhD, Institute of Social Medicine, Occupational Health and Public Health, University of Leipzig, Leipzig, Germany; Daphna Levinson, PhD, Mental Health Services, Ministry of Health, Jerusalem, Israel; Giovanni de Girolamo, MD, IRCCS Centro S. Giovanni di Dio Fatebenefratelli, Brescia, Italy; Yutaka Ono, MD, MD, IRCCS Centro S. Giovanni di Dio Fatebenefratelli, Brescia, Italy; Yutaka Ono,
PhD, National Center for Neurology and Psychiatry, Tokyo, Japan; Ron de Graaf, PhD, MSc, Trimbos Institute, Netherlands Institute of Mental Health and Addiction, Utrecht, The Netherlands; Mark Oakley Browne, FRANZCP, PhD, Department of Health, Melbourne, Victoria, Australia; Brendan Bunting, PhD, Psychology, Research Institute, University of Ulster, Londonderry, UK; Miguel Xavier, MD, PhD, Chronic Diseases Research Center (CEDOC) and Department of Mental Health, Faculdade de Ciências Médicas, Universidade Nova de Lisboa, Lisbon, Portugal; Josep Maria Haro MD, MPH, PhD, Parc Sanitari Sant Joan de Déu, CIBERSAM, University of Barcelona, Barcelona, Spain; Ronald C. Kessler, PhD, Department of Health Care Policy, Harvard Medical School, Boston, USA

Correspondence: Ronny Bruffaerts, Universitair Psychiatrisch Centrum Katholieke Universiteit Leuven (UPC-KUL), campus Leuven, Herestraat 49, B-3000 Leuven, Belgium. Email: ronny.bruffaerts@med.kuleuven.be.

First received 19 Nov 2013, final revision 15 Apr 2014, accepted 27 Jun 2014

\section{Funding}

This report is carried out in conjunction with the World Health Organization World Mental Health (WMH) Survey Initiative. These activities were supported by the United States National Institute of Mental Health (R01MH070884), the Mental Health Burden Study: Contract number HHSN271200700030C, the John D. and Catherine T. MacArthur Foundation, the Pfizer Foundation, the US Public Health Service (R13-MH066849, R01MH069864, and R01 DA016558), the Fogarty International Center (FIRCA R03-TW006481), the Pan American Health Organization, the Eli Lilly \& Company Foundation, Ortho-McNeil Pharmaceutical, Inc., GlaxoSmithKline, Bristol-Myers Squibb and Shire. A complete list of WMH publications can be found at http://www.hcp.med.harvard.edu/wmh/. The São Paulo Megacity Mental Health Survey is supported by the State of São Paulo Research Foundation (FAPESP) Thematic Project Grant 03/00204-3. The Bulgarian Epidemiological Study of common mental disorders EPIBUL is supported by the Ministry of Health and the National Center for Public Health Protection. The Chinese World Mental Health Survey Initiative is supported by the Pfizer Foundation. The Shenzhen Mental Health Survey is supported by the Shenzhen Bureau of Health and the Shenzhen Bureau of Science, Technology, and Information. The Colombian National Study of Mental Health (NSMH) is supported by the Ministry of Social Protection. The ESEMeD project is funded by the European Commission (Contracts QLG5-1999-01042; SANCO 2004123), the Piedmont Region (Italy), Fondo de Investigación Sanitaria, Instituto de Salud Carlos III, Spain (FIS 00/0028), Ministerio de Ciencia y Tecnología, Spain (SAF 2000-158-CE), Departament de Salut, Generalitat de Catalunya, Spain, Instituto de Salud Carlos III (CIBER CB06/02/0046, RETICS RD06/0011 REM-TAP), and other local agencies and by an unrestricted educational grant from GlaxoSmithKline. The Epidemiological Study on Mental Disorders in India was funded jointly by Government of India and WHO. Implementation of the Iraq Mental Health Survey (IMHS) and data entry were carried out by the staff of the Iraqi MOH and MOP with direct support from the Iraqi IMHS team with funding from both the Japanese and European Funds through United Nations Development Group Iraq Trust Fund (UNDG ITF). The Israel National Health Survey is funded by the Ministry of Health with support from the Israel National Institute for Health Policy and Health Services Research and the National Insurance Institute of Israel. The World Mental Health Japan (WMHJ) Survey is supported by the Grant for Research on Psychiatric and Neurological Diseases and Mental Health (H13-SHOGAl-023, H14-TOKUBETSU-026, H16-KOKORO-013) from the Japan Ministry of Health, Labour and Welfare. The Lebanese National Mental Health Survey (LEBANON) is supported by the Lebanese Ministry of Public Health, the WHO (Lebanon), Fogarty International, anonymous private donations to IDRAAC, Lebanon, and unrestricted grants from Janssen Cilag, Eli Lilly, GlaxoSmithKline, Roche and Novartis. The Mexican National Comorbidity Survey (MNCS) is supported by The National Institute of Psychiatry Ramon de la Fuente (INPRFMDIES 4280) and by the National Council on Science and Technology (CONACYT-G30544- H), with supplemental support from the PanAmerican Health Organization (PAHO). Te Rau Hinengaro: The New Zealand Mental Health Survey (NZMHS) is supported by the New Zealand Ministry of Health, Alcohol Advisory Council and the Health Research Council. The Nigerian Survey of Mental Health and Wellbeing (NSMHW) is supported by the WHO (Geneva), the WHO (Nigeria) and the Federal Ministry of Health, Abuja, Nigeria. The (Geneva), the WHO (Nigeria) and the Federal Ministry of Health, Abuja, Nigeria. The
Northern Ireland Study of Mental Health was funded by the Health \& Social Care Research \& Development Division of the Public Health Agency. The Romania WMH study projects 'Policies in Mental Health Area' and 'National Study regarding Mental Health and Services Use' were carried out by National School of Public Health \& Health Services Management (former National Institute for Research \& Development in Health), with technical support of Metro Media Transilvania the National Institute of Statistics-National Centre for Training in Statistics, SC. Cheyenne Services SRL, Statistics Netherlands and were funded by Ministry of Public Health (former Ministry of Health) with supplemental support of Eli Lilly Romania SRL. The South Africa Stress and Health Study (SASH) is supported by the US National Institute of Mental Health (R01-MH059575) and National Institute of Drug Abuse with supplemental funding from the South African Department of Health and the University of Michigan. The Ukraine Comorbid Mental Disorders during Periods of Social Disruption (CMDPSD) study is funded by the US National Institute of Mental Health (RO1-MH61905). The US National Comorbidity Survey Replication (NCS-R) is supported by the National Institute of Mental Health (NIMH; U01-MH60220) with supplemental support from the National Institute of Drug Abuse (NIDA), the Substance Abuse and Mental Health Services Administration (SAMHSA), the Robert Wood Johnson Foundation (RWJF; Grant 044708) and the John W. Alden Trust

\section{Acknowledgements}

We thank the WMH staff for assistance with instrumentation, fieldwork and data analysis.

\section{References}

1 Demyttenaere K, Bruffaerts R, Posada-Villa J, Gasquet I, Kovess V, Lepine JP, et al. Prevalence, severity and unmet need for treatment of mental disorders in the World Health Organization World Mental Health (WMH) Surveys. JAMA 2004; 291: 2581-90.

2 Hu TW. Financing global mental health services and the role of WHO. J Ment Health Policy Econ 2003; 6: 145-7.

3 Wang PS, Aguilar-Gaxiola S, Alonso J, Angermeyer MC, Borges G, Bromet EJ, et al. Use of mental health services for anxiety, mood, and substance disorders in 17 countries in the WHO world mental health surveys. Lancet 2007; 370: 841-50.

4 Mojtabai R. Unmet need for treatment of major depression in the United States. Psychiatr Serv 2009; 60: 297-305.

5 Wang PS, Angermeyer M, Borges G, Bruffaerts R, Tat Chiu W, De Girolamo G, et al. Delay and failure in treatment seeking after first onset of mental disorders in the World Health Organization's World Mental Health Survey Initiative. World Psychiatry 2007; 6: 177-85. 
6 Wittchen HU, Jacobi F. Size and burden of mental disorders in Europe - a critical review and appraisal of 27 studies. Eur Neuropsychopharmacol 2005; 15: $357-76$.

7 Regier DA, Narrow WE, Rae DS, Manderscheid RW, Locke BZ, Goodwin FK The de facto US mental and addictive disorders service system. Epidemiologic catchment area prospective 1-year prevalence rates of disorders and services. Arch Gen Psychiatry 1993; 50: 85-94.

8 Klerman GL, Olfson L, Leon AC, Weissman MM. Measuring the need for mental health care. Health Aff 1992; 11: 23-33.

9 Kessler RC, Frank RG, Edlund M, Katz SJ, Lin E, Leaf P. Differences in the use of psychiatric outpatient services between the United States and Ontario. N Engl J Med 1997; 336: 551-7.

10 Druss BG, Wang PS, Sampson NA, Olfson M, Pincus HA, Wells KB, et al. Understanding mental health treatment in persons without mental disorders. Arch Gen Psychiatry 2007; 64: 1196-203.

11 Shapiro S, Skinner EA, Kramer M, Steinwachs DM, Regier DA. Measuring need for mental health services in a general population. Med Care 1985; 23 1033-43.

12 Lin E, Goering PN, Lesage A, Streiner DL. Epidemiologic assessment of overmet need in mental health care. Soc Psychiatry Psychiatr Epidemiol 1997: 32: 355-62.

13 Bijl R, de Graaf R, Hiripi E, Kessler RC, Kohn R, Offord D, et al. The prevalence of treated and untreated mental disorers in five countries. Health Aff 2003; 22: $122-33$

14 Sareen J, Stein MB, Campbell DW, Hassard T, Menec V. The relation between perceived need for mental health treatment, DSM diagnosis, and quality of life: a Canadian population-based perspective. Can J Psychiatry 2005; 50 87-94.

15 Angold A, Costello EJ, Farmer EMZ, Burns BJ, Erkanli A. Impaired but undiagnosed. J Am Acad Child Adolesc Psychiatry 1999; 38: 129-37.

16 Ross HE, Lin E, Cunningham J. Mental health service use: a comparison of treated and untrated individuals with substance use disorders in Ontario. Can J Psychiatry 1999; 44: 570-7.

17 Henderson S, Korten A, Medway J. Non-disabled cases in a national survey. Psychol Med 2001; 31: 769-77.

18 American Psychiatric Association. Diagnostic and Statistical Manual of Mental Disorder (4th edn) (DSM-IV). APA, 1994

19 World Bank. World Bank Data and Statistics. World Bank, 2008.

20 Heeringa S, Wells JE, Hubbard F, Mneimneh ZN, Chiu WT, Sampson NA, et al. Sample designs and sampling procedures. In The WHO World Mental Health Surveys: Global Perspectives on the Epidemiology of Mental Disorders (eds RC Kessler and TB Üstün): 14-32. Cambridge University Press, 2008.

21 Pennell BE, Mneimneh ZN, Bowers A, Chardoul S, Wells JE, Viana MC, et al. Implementation of the World Mental Health Surveys. In The WHO World Mental Health Surveys: Global Perspectives on the Epidemiology of Mental Disorders (eds RC Kessler and TB Üstün): 33-57. Cambridge University Press, 2008
22 Harkness J, Pennell BE, Villar A, Gebler N, Aguilar-Gaxiola S, Bilgen I. Translation procedures and translation assessment in the World Mental Health Survey Initiative. In The WHO World Mental Health Surveys: Global Perspectives on the Epidemiology of Mental Disorders (eds RC Kessler and TB Üstün): 91-113 Cambridge University Press, 2008

23 Kessler RC, Ustun TB. The World Mental Health (WMH) Survey Initiative Version of the World Health Organization (WHO) Composite International Diagnostic Interview (CIDI). Int J Methods Psychiatr Res 2004; 13: 93-121.

24 Haro JM, Arbabzadeh-Bouchez S, Brugha TS, de Girolamo G, Guyer ME, Jin R, et al. Concordance of the Composite International Diagnostic Interview Version 3.0 (CIDI 3.0) with standardized clinical assessments in the WHO World Mental Health surveys. Int J Methods Psychiatr Res 2006; 15: 167-80.

25 Aoun, Pennebaker D, Wood C. Assessing population need for mental health care: a review of approaches and predictors. Ment Health Serv Res 2004; 6 : 33-46.

26 Andrews G, Henderson S. Unmet need in Psychiatry: Problems, Resources, Responses. Cambridge University Press, 2000.

27 Wolter KM. Introduction to Variance Estimation. Springer, 1985.

28 Simon GE, Von Korff M. Recall of psychiatric history in cross-sectional surveys: implications for epidemiologic research. Epidemiol Rev 1995; 17: 221-7.

29 Petrou S, Murray L, Cooper P, Davidson LL. The accuracy of self-reported healthcare resource utilization in health economic studies. Int J Technol Assess Health Care 2002; 18: 705-10.

30 Evans-Lacko S, Knapp M, McCrone P, Thornicroft G, Mojtabai R. The mental health consequences of the recession: economic hardship and employment of people with mental health problems in 27 European countries. PLOS One 2013; 8: e69792.

31 ten Have M, Nuyen J, Beekman A, de Graaf R. Common mental disorders severity and its association with treatment contact and treatment intensity for mental health problems. Psychol Med 2013; 43: 2203-13.

32 Graaf $\mathrm{R}$ de, Have $\mathrm{M}$ ten, Tuithof $\mathrm{M}$, Dorsselaer $\mathrm{S}$ van. First-incidence of DSM-IV mood, anxiety and substance use disorders and its determinants: results from The Netherlands Mental Health Survey and Incidence Study-2. J Affect Disord 2013; 149: 100-7.

33 Kessler RC, Price RH. Primary prevention of secondary disorders: a proposal and agenda. Am J Community Psychol 1993; 21: 607-33.

34 Waza K, Graham AV, Zyzanski SJ, Inoue K. Comparison of symptoms in Japanese and American depressed primary care patients. Fam Pract 1999, 16: $528-33$

35 Maercker A. Association of cross-cultural differences in psychiatric morbidity with cultural values a secondary data analysis. German J Psychiatry 2001; 4: 17-23.

36 Druss BG. Rising mental health costs: what are we getting for our money? Health Aff 2006; 25: 614-22. 